\title{
CRISIS AND GOVERNANCE. VALUATION OF SKILLS AS A FACTOR OF ORGANIZATIONAL COHESION
}

\author{
Olivier Saissi ${ }^{\mathrm{a}}$, Jocelyne Napoli ${ }^{\mathrm{b}}$ \\ ${ }^{a}$ Université de Toulon, France, \\ e-mail: oliviersaissi@yahoo.fr \\ ${ }^{\mathrm{b}}$ Université Paul Sabatier, Toulouse III, France, \\ e-mail: Jocelyne.napoli@univ-tlse3.fr
}

\begin{abstract}
Purpose: The growing of the international exchanges and the liberalization of many economic sectors lead to the instability of the relation between employer - employee. At any time, this one is likely to be broken to allow the company to face economic or financial requirements. In such a context, how to have motivated employees in an organization which can rapidly exclude them? The aim of this analysis is to evaluate in which measurements the recognition of skills seems a suggestion for solution. Any worker invests himself in his work because he reinforces his employability. This factor will enable him to reinforce the probability of finding a new employment in case he has suddenly been laid off.
\end{abstract}

Methodology and approach: The starting point of this reflection rests on two hypothesis:

1. Any organization needs motivated employees in order to get a competitive advantage.

2. The motivation of the employees can be obtained even when the objectives of the employee and those of the company are divergent. The homogeneity of the methods used and the heterogeneity of the goals constitute the new challenge of the organizations to ensure their durability. Considering the hypothesis and the aim of the analysis, a trans field study, including sociology/ management/labor law has been led to highlight a possible adhesion of the employees to the objectives of an organization evolving in an unstable environment.

Findings : The skills recognition and the reinforcement of the employability seem to reply to the problems posed. However, the implementation of such a process is conditioned with various elements among which an fair definition of the criteria allowing the employees to have the feeling of a right recognition.

Implications for further research : The validation of the study's results could be get by the control of a comparative study between two similar organizations. One will implement a process of recognition of competences, the other preserving a more traditional way of human resources managing. For a better evaluation of the impact of the difference between the two ways of managing, the companies tested will be selected within service industry.

Keywords: complexity, crisis, employability, governance, management, skills recognition

Paper type: Conceptuel Paper 
CRISIS

AND

GOVERNANCE

Olivier Saissi

Jocelyne Napoli

Figure 1.

Causal triptych of crisis

\section{The employability: its origin and characteristics}

The employability defines itself as the capacity in which an individual manages to find a job when he is of working age (Rump and Sattelberger, 2010). The employability is generally linked to experience and skills which stem from it. In fact, the recognition and value of experience appears as a prerequisite in the evaluation of the employability.

\subsection{Suitability of employability}

Promoting research and obtaining jobs, the employability is relevant on the condition that in time of crisis, an individual is placed in the situation of finding a job and that the latter is important for him (McQuaid et al., 2013).

Any period of crisis, known by a company, is characterized, generally, by the causal triptych shown in Figure 1.

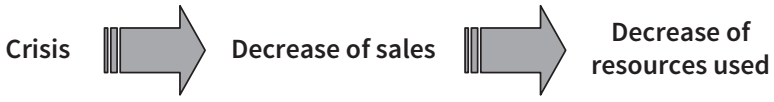

Particular economic circumstances generate a change in the volume of products sold by the company. The resulting financial loss creates a crisis for the company, which in return responds by limiting the quantity and quality of the used resources. Among the latter, the human resources suffer various impacts, as they are often considered to be the most flexible. The range of actions is very wide, from the decrease in acquired advantages or remuneration, to deletion of posts and jobs.

Such a context generally leads to questioning the traits and skills held by the company. A qualitative evolution translates to a substitution of skills exceeded by new ones. A quantitative evolution finds its shape in a reduction of personnel.

So, within an organization, every person is vulnerable to have his status questioned and thereby lose his job.

As far as knowing if unemployment makes the individual in the position of searching for another job, the answer can only be affirmative. If this is not the case, the individual didn't look for any previous job. The relevance of this answer, however, remains correlated with the absence of substitute income, which would allow the individual to stay unemployed. (Lumley and Wilkinson, 2013).

However, having a job is essential for an individual to be able to satisfy his needs and desires. In the event of a loss of professional activity, formalization of skills relevant to employability is an essential stage to favor a swift professional re-integration. 
1.2. Recognition of skills

The recognition of skills characterizes the experience which an individual has acquired during the implementation of a process and implies that this will allow him to face future situations and problems (Hind, 2013). Without falling into absolute determinism, we can however note a reproducibility of the solutions encountered to solve or prevent potentially present or future problems (EalesWhite, 2013).

The recognition of skills can take three general forms (Dalkir and Liebowitz, 2011):

- an ex ante allocation,

- an ex post validation,

- an inductive valorisation.

\subsubsection{An ex ante allocation}

The ex ante allocation of a set of skills to an individual presupposes a double movement consisting, first of all, of an increase of the cognitive capital followed by an application of the acquired notions (Desouza and Paquette, 2011). In this particular case, theory precedes experience. The ex ante allocation reaches an illustration through the diploma-awarding formation. The company fully or partly finances a training program followed by a certificate, a statement or a diploma awarded to the employee in the term of the process. The value of the acquired skills is important, for the award is acknowledged within the company, within the professional sector or within an educational system.

In France, the principle of the vocational training and its financing by companies are an example of this ex ante allocation. Once the title of recognition has been obtained, the employee is capable of acquiring a new post in his company or in another organization.

\subsubsection{An ex post validation}

At first, the ex post validation implies the acquisition of a set of formal and informal skills within the framework of the static and dynamic routines' realization. As the employee's career evolves, the individual acquires skills and additional responsibilities which are not necessarily recognized in the company and which, considering their specific characters, are also not recognized by other organizations. From then on, to obtain a global recognition, the acquired experience gains to be validated by an authority figure recognized by all as an educational establishment. The latter evaluates the employee's skills, compares them to those possessed by students following an initial formation and, according to circumstances, delivers full or part of a diploma. This title, albeit identical to others, will allow for a formalization of said acquired skills.

\begin{tabular}{r} 
CRISIS \\
AND \\
GOVERNANCE \\
\hline Olivier Saissi \\
Jocelyne Napoli
\end{tabular}


CRISIS

AND

GOVERNANCE

Olivier Saissi

Jocelyne Napoli

\subsubsection{An inductive appreciation}

The inductive appreciation implies an indirect acknowledgment of an individual's skills through the achievements he has made. It is in the light of the obtained performances and constructed result that his skills will be estimated. It is then obvious that for such an appreciation to take place, a formalization of the achieved processes will be mandatory, in particular by means of certification. This stage is essential to obtain a global recognition of the undertaken work and the skills acquired in the process. Without this element, the appreciation is meaningless.

The institution of the appreciation of skills forms an evolution of the organization's proper functioning. This dynamic generates constraints to be respected and limits to be breached.

\section{Constraints and limits of appreciation}

The appreciation of an employee's skills is a way to strengthen its employability. The company must therefore set up various processes in order to obtain the recognition of the staff members' knowledge and know-how (McInerney, 2010). At the same time, the employee is going to start expecting compensation for the acquired expertise.

\subsection{Some constraints}

The formalization of the actors' skills within an organization is going to start, according to a Newtonian reaction principle, a set of disturbances which the organizational structure will have to face (Treu, 2013).

\subsubsection{Implementation of process of recognition}

The realization of any action, the implementation of any process requires the actors to resort to know-how. Within the framework of the implementation of a skills formalization process, it is important that in every stage or element of the production realized by the employee there exists a set of evaluation criteria towards the obtained performances which, beyond a binary conception of success - failure, allows to specify quality and quantity of obtained results (Prax, 2011). Furthermore, the legitimacy of such a system can only be obtained at the condition that it is the object of an accepted and shared conception between management and actors (Roulleaux-Ducage, 2011).

In the case of a disagreement, differences are going to appear within quality of the employee's skills. In the case of a failure, the latter can argue with the disposal of a defective material hindering the progress of his mission. In the case of a success, the management can mention the quality of the material alleviating the employee's faults or missing skills (Schwab, 2010). 
This debate is far from being theoretical, as shown in the case of airplane construction. During its conception, the Airbus A320 was endowed with a computer system verifying the pilots' operations and, if need should arise, modifying or refusing them if it would jeopardize the aircraft's integrity. Therefore, we are entitled to question the quality of an A 320's touchdown. Was it perfect because the pilots are competent or because the computer managed to correct the incompetent pilots' errors?

\subsubsection{An evolution of the social relationship management}

The heterogeneousness of the skills and the multiple dynamics of their acquisitions inevitably lead to the implementation of an individual skill management and formalization. Beyond the completed work and obtained results, the value of an individual will shine through his know-how, what he actually does and what he can really do (Thom, 2011).

To be effective, such a process has to answer to two requirements:

- It must be continuous instead of sequential as an annual interview based on obtained results can be. Indeed, skills are acquired or confirmed at any stage of the production and cannot focus only on a final state.

- It has to be pro-active and capable of continuously assimilating new skills possessed or not by a member of the organization. Otherwise, a static and predefined construction of the skills basis could only finally lead to the rigidity of an organization where everyone believes they know everything.

Once the system of recognition is established, it must implement two variables to be fully effective:

- The first opening concerning the appreciation of the acquired skill: this stage forms the awaited counterpart by the employee regarding the increase of his potential. Besides the reward of the initial acquisition, the valorization must also favor future assets. Such a process can only work if the actor estimates the obtained counterpart as being fair. Should the opposite occur, the initiated dynamic is inhibited. Because of the necessity of work with the individual's expectations and the organization's helplessness, the valorization's main trait is of being multi-form.

- The second variable integrates the valorization's holistic dimension and the feeling of equity attached to it. Every actor is going to wait for a legitimate individual reward following the increase of his skills while this state was generally only possible due to competition against other members of the organization. The stimulation of the actor in his learning dynamics seems linked to the recognition of the collaborative nature of this one. In the absence of this association, an iatrogenic reaction of the group of acquaintances will hinder the cognitive process. 
CRISIS

AND

GOVERNANCE

Olivier Saissi

Jocelyne Napoli
Besides the respect for new constraints, the introduction of this new mode of social relationship management may be pitted against unexpected obstacles.

\subsection{Some limits}

In consideration of the systematic nature of the organization, the limits find two origins.

\subsubsection{An endogenous opportunism}

In order to strengthen his position and strive towards maximizing his benefits, any individual will behave in a way that will allow him to strengthen his skills by practicing new routines and dismissing operations he masters because they do not strengthen his know-how. Taking a hospital as reference, this attitude would reflect in the behavior of a doctor, who would constantly seek to treat new diseases and refuse to take care of patients with flu on the grounds that prescription of antibiotics is time-consuming and will not result in new skills mastery.

Ultimately, there may be differences between the objectives of an organization and those of the individuals forming it. In the light of qualitative or quantitative saturation of required skills, the individual is likely to leave the organization for another. If the structural cohesion can be maintained by this homeostatic phenomenon, the organization is, however, in a situation of loss of cognitive investment and having to replace it.

\subsubsection{An exogenous disturbance}

By proceeding to the formalization and recognition of skills, organizations end up in a situation of know-how standardization, whatever the specificities of their production are. From informal knowledge thus perceived as specific, we end up with a standardized set of skills promoting inter organizational migrations (Eales-White, 2013). If originally these flows could be wanted by organizations knowing a period of crisis and wishing to reduce the number of employees, limits appear when their departure is premature. Phenomena all the more fatal as the individuals are welcomed by competitors of the original organization.

To end this analysis, the organization is placed in an unstable situation. The formalization and recognition of skills come along with the emergence of opportunistic processes in an individual, susceptible to make his own interest prevail at the expense of those of the organization. If, in terms of the individuals' management and the preservation of the organizational cohesion within an unstable and complex environment, the formalization and the recognition of skills are essential, it does not seem enough. One of the complementary ways could be the framework of a kind of strategic partnership between organization and actors, where the fates of one and another would be merged. "Neither you without me nor me without you" can become an organizational maxim where the scope and modalities remain to be defined. 
3. Summary

The increasing complexity of the environment, in which the companies evolve, places them in the situation of a dynamic management of the resources used to carry out their production. Among these resources, are human resources? The managers are placed in a difficult situation: how to motivate employees who can, at any time, find themselves without employment? One of the suggested solutions is the employability. This principle allows the recognition of the expert knowledge held by any employee in order to facilitate its professional reintegration in the case of a job loss or unemployment . How to recognize expert knowledge? When to recognize it? Which are the limits of the recognition? Such are the questions to which this analysis tries to carry an answer, for at the same time allowing to manage the entrepreneurial resources and to obtain a continue employees" adhesion to the main company's goals.

The economical recession induced by the so-called subprime crisis, has created an extremely complex situation to understand and is characterized by a chain reaction of company failures.

Since then, against an ever growing complex system, tools and models used to insure the sustainability of organizations have proved themselves flawed.

The organization is then led to acknowledge a decreasing probability of achieving its goals which take, in particular, the shape of a time-framed setting for its activity, and an upholding of its values and culture.

Against this unstable situation, which at any time may lead to the extinction of the organization's structure, there is a problem of consistency maintenance. How can the personnel be motivated and ensure their involvement in achieving pre-defined goals even though in a short laps of time, they may find themselves unemployed?

At first this reconciliation seems very difficult. Indeed, the personnel are looking for stable situations that would allow them to plan how to reach their personal and professional goals. The perception of this scheme as time-related allows the inference. On the other hand, the reconciliation can only develop an opportunistic attitude taking the shape of a privilege given to the accomplishment of personal goals thus harming those of the organization. This disengagement is at the origin of a reduction in the performance of the organization and therefore strengthens the fragility of its situation.

In order to leave such a potentially downward spiral in which the crisis induces demotivation reinforcing the crisis itself, it is appropriate to reformulate the personnel's expectations. To the prospect of a long-term employment in the company, one needs to look for an alternative that satisfies both parties.

Within this context, one can ask oneself about the legitimacy of employability as a common ground satisfying the various expectations.

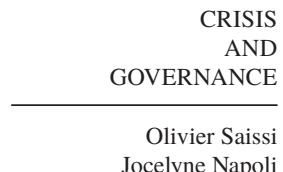

Olivier Saissi
Jocelyne Napoli Jocelyne Napoli 
CRISIS

AND

GOVERNANCE

Olivier Saissi

Jocelyne Napoli

\section{References}

Dalkir, K., J. Liebowitz, J. (2011), Knowledge Management in Theory and Practice, MIT Press, Cambridge.

Desouza, K., Paquette, S. (2011), Knowledge Management, Facet Publishing, London.

Eales-White, R. (2013), Maximize employability and career success, CreateSpace Independent Publishing Platform.

Hind, D. (2013), Employability Skills, Business Education Publishers Ltd, Sunderland.

Lumley, M., Wilkinson, J. (2013), Developing Employability for Business, OUP Editors, Oxford.

McInerney, C. (2010), Rethinking Knowledge Management: From Knowledge Objects to Knowledge Processes, Springer-Verlag, Berlin.

McQuaid, R., Green, A., Dawson M. (2013), Employability and local labor markets, Routledge, Oxford.

Prax, J.Y. (2011), Le manuel du knowledge Management, Dunod, Paris.

Roulleaux-Ducage, M. (2011), Organisation 2.0 Le Knowledge Management nouvelle génération, Eyrolles, Paris.

Rump, J., Sattelberger T. (2010), Employability Management 2.0, Wissenschaft \& Praxis, Frankfurt.

Schwab, A. (2010), Managementwissen, Springer, Berlin. DOI: http://www.dx.doi. org/10.1007/978-3-642-04488-5

Thom, M. (2011), Business Incubation -How to Manage the Know-how Transfer, Grin Verlag, Cambridge.

Treu, T. (2013), Employability per persone e imprese. Percorsi di outplacement, Guerini, Milano. 